\title{
Avaliação de Desempenho de Gestão de Recursos Humanos no Setor Público
}

\section{Performance Evaluation of Human Resources Management in Public Sector}

\author{
Paula Cristina Leite Guesser \\ Mestranda em Contabilidade \\ Universidade Federal de Santa Catarina - UFSC \\ Campus Reitor João David Ferreira Lima, s/n - Trindade, Florianópolis - SC, CEP 88040-900 \\ E-mail: paulalguesser@gmail.com
}

Sandra Rolim Ensslin

Doutora em Engenharia de Produção

Universidade Federal de Santa Catarina - UFSC

Campus Reitor João David Ferreira Lima, s/n - Trindade, Florianópolis - SC, CEP 88040-900

E-mail: sensslin@gmail.com

\author{
Sergio Murilo Petri \\ Doutor em Engenharia de Produção \\ Universidade Federal de Santa Catarina - UFSC \\ Campus Reitor João David Ferreira Lima, s/n - Trindade, Florianópolis - SC, CEP 88040-900 \\ E-mail: smpetri@gmail.com
}

\begin{abstract}
Resumo
A orientação de serviços com foco nos resultados passou a ser adotada no setor público por meio de práticas de gestão estratégica como a Avaliação de Desempenho (AD) de Recursos Humanos (RH) para aprimorar a eficiência da prestação de serviços públicos. Assim, esta pesquisa tem como objetivo analisar as características das publicações científicas, em língua inglesa, que abordam o tema referente à Avaliação de Desempenho de Recursos Humanos no Setor Público, para gerar conhecimento e identificar lacunas e possibilidades de contribuições para futuras pesquisas. Trata-se de um estudo de abordagem qualitativa, feito por meio da seleção e análise bibliográfica de artigos científicos com base na ferramenta Knowledge Development Process-Constructivist (ProKnow-C). Por meio da análise do Portfólio, composto por 21 artigos, foram encontrados estes resultados: evidenciação da motivação como a principal função da Avaliação de Desempenho de Recursos Humanos do setor público; falta de vinculação dos indicadores às estratégias da organização e ao ambiente onde essa está inserida; concentração das pesquisas na etapa de design do Sistema de $\mathrm{AD}$, impossibilitando o feedback e o aprendizado, tanto por parte dos servidores, quanto dos gestores de RH; e geração de oportunidades de pesquisa para teóricos e desafios para gestores com base na identificação de falhas no processo de Avaliação de Desempenho. Portanto, as pesquisas precisam avançar para a análise dos processos necessários para o funcionamento do Sistema de Avaliação de Desempenho de Recursos Humanos no setor público, de forma a evoluir para os estágios de implementação, uso e revisão, preferencialmente com a participação de todos os stakeholders.
\end{abstract}

Palavras-chave: Avaliação de Desempenho. Recursos Humanos. Setor Público. Revisão da Literatura.

\begin{abstract}
The service orientation focused on the results was adopted in the public sector by means of strategic management practices such as a Performance Evaluation (PE) of Human Resources $(H R)$ to improve the efficiency of service delivery. Thus, this research aims to analyze the
\end{abstract}


characteristics of the scientific publications in English language, which address the theme of Human Resource Performance Evaluation in Public Sector, to generate knowledge and identify gaps and possibilities for contributions to future research. This is a qualitative approach study, done through the selection and bibliographic analysis of scientific articles based on the instrument Knowledge Development Process-Constructivist (ProKnow-C). Through the analysis of the Portfolio, composed of 21 articles, these results were found: evidence of motivation as the main function of the Performance Evaluation of Human Resources in public sector; lack of linkage of the indicators to the strategies of the organization and the environment where it is inserted; concentration of research in the design stage of the AD System, making it impossible for feedback and learning, as much of part of the servers as of the HR managers; and generation of research opportunities for theorists and challenges for managers based on the identification of failures in the Performance Evaluation process. Thus, the research needs to proceed to the analysis of the processes necessary for the functioning of the Human Resources Performance Evaluation System in public sector, in order to progress to the stages of implementation, use and review, preferably with the participation of all stakeholders.

Keywords: Performance evaluation. Human Resources. Public sector. Literature revision.

\section{INTRODUÇÃO}

Nas últimas três décadas, a demanda pela excelência no desempenho do setor público tornou-se prioridade comum em sociedade (VERMEEREN, 2017). Nesse contexto, houve forte movimento para a prestação de serviços do setor público, focada na maximização do bem-estar social e acompanhada pela Avaliação de Desempenho (AD) de forma mais pontual, precisa e com fins recompensatórios (TANWIR, CHAUDHRY, 2016). Esse movimento, em diferentes países, está relacionado à Nova Gestão Pública, orientada para o desempenho dessa prestação de serviços por meio da ênfase no controle de resultados (TER BOGT, 2003; FRENCH, GOODMAN, 2012; VERMEEREN, 2017), com base na adoção de práticas do setor privado para melhorar a eficiência dos serviços e da gestão organizacional (ABU-DOLEH, WEIR, 2007; CONWAY et al., 2016; TANWIR, CHAUDHRY, 2016).

Essas reformas no setor público estão acontecendo há mais tempo na Europa e nos Estados Unidos do que no Brasil e em outros países emergentes. No Brasil, por exemplo, destaca-se o Plano Diretor da Reforma do Aparelho do Estado (21 de setembro de 1995), aprovado pela Presidência da República, que foi precursor no estabelecimento de diretrizes com foco no controle dos resultados com base na Avaliação de Desempenho.

A prática da Avaliação de Desempenho (AD) objetiva a melhoria contínua das atividades organizacionais e o alcance de seus objetivos estratégicos por meio do acompanhamento do desempenho nos indicadores do Sistema, num processo de aprendizagem constante dos gestores e colaboradores para gestão e crescimento do desempenho humano como o do próprio Sistema de AD (NEELY, GREGORY, PLATTS, 1995; BOURNE et al., 2000; GHALAYNI, NOBLE, 1996; FERREIRA, OTLEY, 2009; ENSSLIN et al., 2010; BITITCI et al., 2012). Assim, os gestores públicos estão cada vez mais interessados na Avaliação de Desempenho para aprimorar a gestão de suas organizações (BEHN, 2003). Salienta-se que, além da influência no desempenho organizacional, a atividade e a gestão promovidas pela Avaliação de Desempenho influenciam o desenvolvimento e uso das capacidades organizacionais e o comportamento das pessoas (FRANCO-SANTOS, LUCIANETTI, BOURNE, 2012).

Pela perspectiva da Teoria Geral dos Sistemas, a Avaliação de Desempenho é capaz de agregar o efeito sinérgico de um Sistema por meio da adoção de medidas definidas de acordo 
com o contexto e as necessidades dos stakeholders (NEELY, GREGORY, PLATTS, 1995; BOURNE et al., 2000; FERREIRA, OTLEY, 2009; CHOONG, 2014). Ou seja, o Sistema de Avaliação de Desempenho precisa ser revisto e aprimorado constantemente para acompanhar esse ambiente globalizado de avanços tecnológicos e com processos de trabalho que atendam às necessidades dos stakeholders envolvidos ou que afetem/interfiram na organização (BOURNE et al., 2000; MICHELI, MARI, 2014).

Pesquisas mostram que organizações que fazem uso da $\mathrm{AD}$, orientada por resultados e remuneração baseada em desempenho de seus servidores, são mais capazes de alcançar seus objetivos estratégicos (DALEY, VASU, 2005). Logo, a modernização da Avaliação de Desempenho dos servidores públicos tornou-se vital para que o serviço público consiga reinventar-se diante dos desafios estratégicos atuais (TANWIR, CHAUDHRY, 2016). Assim, a gestão de Recursos Humanos deixou de ter papel operacional para assumir importante papel na gestão estratégica das organizações (DALEY, VASU, 2005; FRENCH, GOODMAN, 2012).

Considerando a relevância dos Recursos Humanos, em especial na área pública que afeta diretamente todos os cidadãos e que pode ser mais bem gerenciada pela Avaliação de Desempenho, esta pesquisa visa responder à seguinte pergunta: Como a análise da literatura científica internacional sobre Avaliação de Desempenho de Recursos Humanos no Setor Público pode contribuir para a evolução dessa área de conhecimento? Para responder à pergunta, tem-se como objetivo geral analisar as características das publicações científicas, em língua inglesa, que abordam o tema referente à Avaliação de Desempenho de Recursos Humanos no Setor Público, para gerar conhecimento e identificar lacunas e possibilidades de contribuições para futuras pesquisas.

O instrumento utilizado para fazer a seleção e análise da literatura sobre o tema foi o Knowledge Development Process-Constructivist (ProKnow-C) por já ter sido utilizado e norteado o desenvolvimento de pesquisas qualitativas como este estudo (VALMORBIDA, CARDOSO, ENSSLIN, 2015; THIEL, ENSSLIN, ENSSLIN, 2017; KREUZBERG, VICENTE, 2018). Quanto à delimitação, a literatura selecionada restringe-se a artigos científicos disponíveis nas bases de dados do Portal de Periódicos da Capes (Scopus, Web of Science e Science Direct), publicados em $1^{\circ}$ de janeiro de 2000 até 31 de março de 2018.

A justificativa da necessidade de se investigar e conhecer o que já foi publicado sobre Avaliação de Desempenho de Recursos Humanos em organizações públicas é enfatizada por Tanwir e Chaudhry (2016) ao manifestarem que a AD dos funcionários públicos tornou-se prática vital para que as organizações alcancem seus objetivos estratégicos. Complementando essa manifestação, Daley e Vasu (2005), Amin et al. (2014), Srivastava e Dhar (2016) e Melton e Meier (2017) defendem a centralidade do capital humano das organizações públicas que, segundo Micheli e Mari (2014), Conway et al. (2016) e Vermeeren (2017), se configuram como a força de trabalho para o desempenho e sucesso da prestação de serviços públicos.

A estrutura deste estudo é composta por esta Introdução; na segunda seção, apresentase a Fundamentação Teórica; na terceira, a Metodologia; na quarta seção, os Resultados; na quinta, aparecem as Conclusões; e, por fim, apresentam-se as Referências.

\section{FUNDAMENTAÇÃO TEÓRICA}

\subsection{Revisão da literatura sobre Avaliação de Desempenho}

As origens da Avaliação de Desempenho remontam ao fim do século XIII e acompanharam a complexidade das formas organizacionais que surgiram a partir da Revolução Industrial com foco na produção em massa, passando para a departamentalização e, finalmente, 
pela especialização do trabalho (GHALAYNI, NOBLE, 1996; BITITCI et al., 2012). Acompanhando as mudanças organizacionais, o foco dos indicadores de desempenho também foram passando por alterações ao longo dos anos: inicialmente, centravam-se em medidas financeiras por meio das análises de orçamento e de custo (aproximadamente de 1880 a 1980) e passaram a ser complementadas por medidas representativas de dimensões multidimensionais como qualidade, tempo, flexibilidade e satisfação do cliente; e culminaram no alinhamento dessas com as estratégias organizacionais (GHALAYNI, NOBLE, 1996, BITITCI et al., 2012; CARNEIRO-DA-CUNHA, HOURNEAUX JR, CORRÊA, 2016). A síntese desses movimentos e incrementos de medidas e aspectos cobertos pela AD é apresentada no Quadro 1.

Identificam-se, assim, algumas tendências no desenvolvimento de um Sistema de Avaliação de Desempenho: a orientação estratégica e multidimensionalidade dos modelos (natureza contextual), inclusão de elementos externos e stakeholders, natureza relacional da gestão de desempenho, mudança da medição do desempenho para gestão de desempenho, foco transformacional, estabelecimento de uma análise da organização como um todo (CARNEIRO-DA-CUNHA, OURNEAX, CORRÊA, 2016). Essa natureza mutável do trabalho, bem como o aumento da concorrência, a iniciativa de melhorias específicas, os prêmios de qualidade, a alteração dos papéis organizacionais e das exigências externas e o poder da tecnologia da informação são as razões da importância da Avaliação de Desempenho (NEELY, 1999).

A $\mathrm{AD}$, portanto, visa entender ao progresso das atividades da organização de modo mensurável e compreender as causas que levaram aos resultados (lógica da causalidade) para definir as medidas que conduzem às ações (LEBAS, 1995). Estudos sobre Avaliação de Desempenho, muitas vezes, tratam de procedimentos e ferramentas que poderiam ajudar as organizações, colaborando com a formulação e revisão estratégica, com a comunicação dos resultados aos stakeholders e com a motivação dos empregados (MICHELI, MARI, 2014).

Quadro 1 - Evolução da Avaliação de Desempenho

\begin{tabular}{|c|c|}
\hline $\begin{array}{l}\text { Fase - Época } \\
\text { aproximada }\end{array}$ & Síntese \\
\hline $\begin{array}{l}\text { Gerenciamento } \\
\text { da produtividade } \\
-1900\end{array}$ & $\begin{array}{l}\text { Período de autocracia, onde a maior preocupação era interna, pois as forças competitivas se } \\
\text { resumiam aos custos, com trabalho manual, poucos chefes, sistema regulado por } \\
\text { regulamentos e mudanças lentas (BITITCI et al., 2012). A preocupação nessa época era } \\
\text { centrada em relatórios financeiros, o foco era operacional, e em } 1930 \text { foi criado por } \\
\text { engenheiros na França o primeiro modelo de avaliação: Tableau de Bord (CARNEIRO-DA- } \\
\text { CUNHA, HOURNEAUX, CORREAA, 2016). A visão de desempenho limitava-se ao lucro } \\
\text { líquido - lógica de custos (LEBAS, 1995). }\end{array}$ \\
\hline $\begin{array}{c}\text { Controle } \\
\text { orçamentário - } \\
1930\end{array}$ & $\begin{array}{l}\text { Período de burocracia, taxa de mudança rápida e previsível, a infraestrutura continua sendo } \\
\text { da própria organização, surgiram as estruturas organizacionais e o foco para competir no } \\
\text { mercado passa a ser a diferenciação (BITITCI et al., 2012). Identifica-se que há razões } \\
\text { internas e externas para a realização de cursos específicos de ação (NEELY, GREGORY, } \\
\text { PLATTS, 1995). A General Electric foi uma das primeiras empresas a usar um modelo que } \\
\text { incluiu indicadores de desempenho não financeiros na década de } 1950 \text { (CARNEIRO-DA- } \\
\text { CUNHA, OURNEAX, CORRÊA, 2016). }\end{array}$ \\
\hline $\begin{array}{c}\text { Avaliação } \\
\text { integrada do } \\
\text { desempenho-- } \\
1970\end{array}$ & $\begin{array}{l}\text { Período onde as organizações são mais flexíveis e informais, com mudanças turbulentas e } \\
\text { descontínuas, organização estruturada por processos e com foco na agregação de valor ao } \\
\text { produto para fidelizar o cliente; o sistema de avaliação é regulado pelas melhores práticas } \\
\text { além das leis e passa a ser usado em organizações públicas, sem fins lucrativos e em } \\
\text { pequenas e médias empresas, surgindo a preocupação com o desempenho ambiental e social } \\
\text { (BITITCI et al., 2012). }\end{array}$ \\
\hline $\begin{array}{l}\text { Gerenciamento } \\
\text { integrado do }\end{array}$ & $\begin{array}{l}\text { É um período de netocracia, a avaliação de desempenho é vista como um sistema social, } \\
\text { voltada para a inovação e propriedade intelectual, o mercado é flexível, transformacional e }\end{array}$ \\
\hline
\end{tabular}


desempenho 1990

em redes, o sistema é regulado pela confiança nos relacionamentos, e com a busca constante na melhoria para atender os clientes (BITITCI et al., 2012). Inclusão de elementos estratégicos nos modelos de avaliação de desempenho, por meio de um controle de gestão global e sistêmico da organização (CARNEIRO-DA-CUNHA, OURNEAX, CORRÊA, 2016), derivados de um ambiente social (BITITCI et al., 2012). São criadas ferramentas como o SMART e o Balanced Scorecard - BSC (CARNEIRO-DA-CUNHA, OURNEAX, CORRÊA, 2016).

Fonte: Bititci et al. (2012); Carneiro-da-Cunha, Hourneax, Corrêa (2016); Lebas (1995); Neely, Gregory, Platts (1995); Ghalayni, Noble (1996).

Segundo Choong (2014), os estudos que desenvolvem/propõem Sistemas de AD devem ser estruturados com base na Teoria Geral de Sistemas para agregar o efeito sinérgico das medidas (indicadores) que devem estar de acordo com as necessidades dos stakeholders que envolvem a organização. Isso acontece porque as organizações são sistemas abertos, formados por subsistemas interdependentes, que são diretamente afetados pelo ambiente (interno e externo).

Assim, o Sistema de Avaliação de Desempenho se refere a um processo dinâmico de aprendizagem e de gestão, que objetiva a melhoria contínua das atividades organizacionais e o alcance de seus objetivos estratégicos por meio do acompanhamento do desempenho nos indicadores do Sistema (NEELY, GREGORY, PLATTS, 1995, BITITCI et al., 2012).

Um Sistema de Avaliação de Desempenho pode ser examinado em três níveis: as medidas de desempenho individuais; o conjunto de medidas de desempenho do Sistema; e a relação entre esse Sistema e o ambiente no qual a organização está inserida e com a qual interage (NEELY, GREGORY, PLATTS, 1995), conforme Figura 1.

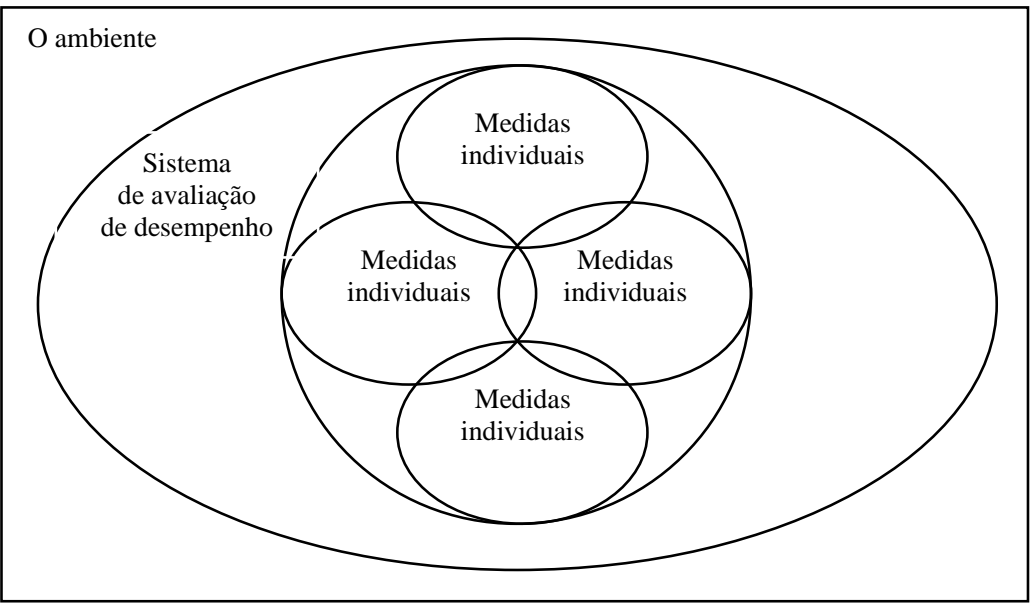

Figura 1 - Níveis abordados pela Avaliação de Desempenho Fonte: Neely, Gregory, Platts (1995, p. 1.229).

Bititci et al. (2012) destacam que o maior desafio do desenvolvimento dos Sistemas de Avaliação de Desempenho reside na compreensão holística da Avaliação de Desempenho como um Sistema Social que permita a aprendizagem em redes autopoiéticas e em múltiplas culturas. Desse modo, as diferentes áreas organizacionais precisam ser exploradas como parte do conjunto, dentro de uma realidade social, e não como um sistema independente e isolado. Por conseguinte, um Sistema de Avaliação de Desempenho não pode ser estático, pois ele precisa ser dinâmico para acompanhar as alterações cada vez mais rápidas e complexas do atual mercado globalizado (GHALAYNI; NOBLE, 1996; MELNYK et al., 2014). 
Esse Sistema abrange o processo de definição dos objetivos e da análise e interpretação dos dados de desempenho (ENSSLIN et al., 2010; MELNYK et al., 2014), tomando as medidas corretivas, caso as metas não sejam cumpridas, para tornar o processamento de informações mais eficiente (CHOONG, 2014) num circuito de aprendizagem capaz de permitir o questionamento das estratégias da organização (MELNYK et al., 2014). Por isso, a manutenção do Sistema de AD também é um exercício cognitivo, um processo sempre de construção para garantir que suas medidas (indicadores) de desempenho estejam adequadas (BOURNE et al., 2000), direcionando, assim, ao alcance das estratégias organizacionais. Essa manutenção ocorre pelo sistema de gerenciamento feito pelos gerentes (LEBAS, 1995).

Questões como: "Que medidas devem ser usadas?" e "Por que são usadas?" devem nortear a construção de um Sistema de Avaliação de Desempenho (LEBAS, 1995). Desse modo, um poderoso sistema de gerenciamento de desempenho precisa ser construído e apoiar medidas que deem autonomia aos indivíduos dentro de seu alcance de controle; reflitam relações de causa e efeito; capacitem e envolvam indivíduos; criem uma base de discussão para apoiar a melhoria contínua; e apoiem a tomada de decisões (LEBAS, 1995).

Logo, medidas de desempenho tradicionais já não são suficientes para representarem o desempenho organizacional nesse mundo de constantes avanços tecnológicos e estruturais. Ghalayni e Noble (1996) afirmam que medidas de desempenho integradas têm as seguintes vantagens frente às medidas tradicionais: baseiam-se na estratégia da organização com medidas financeiras e não financeiras, aplicam-se a todos os colaboradores, ligam as áreas de medição de desempenho às áreas operacionais, utilizam métricas mais simples, tempestivas, sem formato fixo (depende dos objetivos), e acompanham mudanças temporais e locais.

A definição da função a qual os gestores querem alcançar por meio da Avaliação de Desempenho determina o conjunto de medidas de desempenho a serem utilizadas (BEHN, 2003). Assim, Behn (2003) destaca oito funções do Sistema de Avaliação de Desempenho na gestão pública, aplicáveis também à gestão privada, conforme Quadro 2.

Quadro 2 - Funções da Avaliação de Desempenho para os gestores públicos

\begin{tabular}{|c|c|}
\hline Função & Descrição da função da avaliação de desempenho \\
\hline Avaliar & $\begin{array}{l}\text { Verificar como está o desempenho da organização é necessário saber qual o(s) seu(s) objetivo(s) } \\
\text { e acerca do progresso desse(s) objetivo (s). }\end{array}$ \\
\hline Controlar & $\begin{array}{l}\text { Verificar se o serviço está adequado, garantindo que os subordinados estão fazendo a coisa } \\
\text { certa. }\end{array}$ \\
\hline Orçar & Ajudar na alocação orçamentária de recursos públicos para as áreas que realmente precisam. \\
\hline Motivar & $\begin{array}{l}\text { Motivar por meio do uso de medidas/metas para executar melhor e proporcionar uma sensação } \\
\text { de realização aos stakeholders, principalmente colaboradores. }\end{array}$ \\
\hline Promover & $\begin{array}{l}\text { Expor não só pontos negativos, mas também pontos positivos das organizações, expondo seus } \\
\text { resultados para reforçar a confiança pública. }\end{array}$ \\
\hline Celebrar & $\begin{array}{l}\text { Alcançar a celebração de forma indireta por meio de funções como motivação, orçamento, } \\
\text { aprendizagem ou promoção, e é muito importante para reconhecer os esforços das pessoas. }\end{array}$ \\
\hline Aprender & $\begin{array}{l}\text { Aprender o porquê a avaliação de desempenho está ou não está funcionando, de forma a utilizar } \\
\text { apenas as medidas suficientes. }\end{array}$ \\
\hline Melhorar & Melhorar a gestão, identificando e corrigindo as áreas onde o desempenho é fraco. \\
\hline
\end{tabular}
Fonte: Behn (2003).

Todos os sete primeiros propósitos do Quadro 2 convergem para a melhoria da gestão (BEHN, 2003). Esse entendimento está alinhado ao conceito de Avaliação de Desempenho como um processo de aprendizagem em resposta ao contexto e às estratégias das organizações.

Embora exista um grande número de artigos sobre Sistemas de Avaliação de Desempenho, esse campo não mudou muito nos últimos anos devido a problemas fundamentais, como a ambiguidade nas definições e a falta geral de convergência entre as áreas do conhecimento (FRANCO-SANTOS et al., 2007; CHOONG, 2014; VAN CAMP, BRAET, 2016). Lebas (1995) menciona que a definição de Desempenho é muito complexa, pois ela não 
é objetiva, mas, sim, contextual e variável até mesmo em negócios homogêneos, pois cada organização define o desempenho de acordo com seus objetivos estratégicos. Além disso, há poucos sistemas integrados, dinâmicos e precisos, porque a maioria não é sensível à mudança do ambiente, não tem infraestrutura integrada e não tem o apoio da alta administração (NUDURUPATI et al., 2011).

Micheli e Mari (2014) também defendem que a Avaliação de Desempenho apresenta falta de fundamentos teóricos sólidos em Ciências Sociais e tentam avançar nesse campo de conhecimento por meio da análise epistemológica, concluindo que a Avaliação de Desempenho deveria ser considerada um insight, e não conhecimento verdadeiro, pois a compreensão do desempenho organizacional é limitado. A etimologia de medição sugere que os Sistemas de Avaliação de Desempenho tenham um número adequado de indicadores para auxiliar a tomada de decisão, em vez de visar representações verdadeiras de desempenho (MICHELI, MARI, 2014).

Já Bourne et al. (2000) salientam que as pesquisas sobre os Sistemas de Avaliação de Desempenho não têm evoluído muito porque a maior parte dos recentes estudos tem se concentrado apenas nos estágios iniciais, sem estudar a implementação e o acompanhamento dos Sistemas. Isso é muito importante para que as organizações revejam continuamente seus objetivos estratégicos.

Dessa forma, Bourne et al. (2000) propõem que o desenvolvimento de um Sistema de Avaliação de Desempenho é composto por quatro fases apresentadas no Quadro 3.

Quadro 3 - Ciclo de vida de um Sistema de Avaliação de Desempenho

\begin{tabular}{ll}
\hline \multicolumn{1}{c}{ Fase } & \multicolumn{1}{c}{ Descrição } \\
\hline 1. Design & Selecionar as medidas de desempenho \\
2. Implementação & Aplicar as medidas de desempenho \\
3. Uso & Utilizar as medidas de desempenho \\
& Rever metas e padrões; \\
2. Revisão & Desenvolver medidas que acompanham as mudanças; \\
& Rever o conjunto de medidas; \\
& Desafiar os pressupostos estratégicos. \\
\hline
\end{tabular}

Fonte: Bourne et al. (2000).

Em síntese, o ciclo de vida de um Sistema de Avaliação de Desempenho é composto pelas seguintes etapas: design, implementação, uso e revisão (BOURNE et al., 2000). Um Sistema de Avaliação de Desempenho possui características, funções e processos essenciais, em que as características se referem aos elementos centrais como às métricas e o suporte de infraestrutura e pessoal; as funções se referem à utilidade do Sistema; e os processos se referem a tudo o que é feito para que o Sistema funcione, desde o design até a revisão do modelo para que se gere informação útil aos gestores. (FRANCO-SANTOS et al., 2007).

De forma convergente ao ciclo de vida do Sistema de Avaliação de Desempenho, Van Camp e Braet (2016) apresentam 36 falhas comuns e correlacionadas que são relatadas na literatura de Avaliação de Desempenho e categorizaram-nas em nível métrico, de estrutura e de gestão, conforme Quadro 4.

Quadro 4 - Falhas do Sistema de Avaliação de Desempenho e classificação

\begin{tabular}{cccc}
\hline Nível & $\begin{array}{l}\mathrm{N}^{\circ} \text { de } \\
\text { falhas }\end{array}$ & Exemplos de falhas & Implicações \\
\hline
\end{tabular}




\begin{tabular}{cclc}
\hline & & $\begin{array}{l}\text { Falta de definição clara, cópia de outras } \\
\text { empresas sem adaptação, foco em métricas } \\
\text { financeiras, conjunto incompleto, falta de } \\
\text { métricas objetivas. }\end{array}$ & $\begin{array}{l}\text { É necessária uma linguagem comum para } \\
\text { promover clareza, precisão e } \\
\text { uniformidade, adaptação das métricas para } \\
\text { a empresa e abordagem mais objetiva. }\end{array}$ \\
Framework & $13 \quad \begin{array}{l}\text { Falta de escopo articulado, dificuldade de } \\
\text { incorporar diferentes dimensões, sobrecarga } \\
\text { de frameworks diversos, falta de feedback e } \\
\text { aprendizado, falta de dados. }\end{array}$ & $\begin{array}{l}\text { É preciso compreender profundamente o } \\
\text { sistema, introduzir feedback e aprender de } \\
\text { acordo com as complexidades dinâmicas. }\end{array}$ \\
& $\begin{array}{l}\text { Falta de compromisso gerencial, falta de } \\
\text { alinhamento com a estratégia, falta de } \\
\text { procedimento formal, falta de apoio de } \\
\text { Tecnologia da Informação - TI, falta de } \\
\text { envolvimento do usuário, grande número de } \\
\text { stakeholders. }\end{array}$ & $\begin{array}{l}\text { É muito importante o apoio da alta } \\
\text { administração e comprometimento com o } \\
\text { sistema. E a participação dos usuários é } \\
\text { essencial para que o sistema seja validado. }\end{array}$ \\
& \multicolumn{2}{c}{ Fonte: Van Camp e Braet (2016). }
\end{tabular}

Destaca-se que a falta de apoio da alta administração pode inviabilizar a adoção de um Sistema de Avaliação de Desempenho ao desencadear as falhas de falta de recursos (financeiro, humano e de TI), falta de envolvimento do usuário e falta de ações reativas e proativas que podem levar à queda do Sistema como um todo (VAN CAMP, BRAET, 2016). Em relação à falta de apoio de TI, Nudurupati et al. (2011) também destacam a importância de um Sistema de Gestão de Informação (SIG) para o sucesso do Sistema, principalmente na fase da implementação. O SIG precisa ser capaz de coletar, analisar e comunicar os dados de forma preditiva e tempestiva, ao mesmo tempo em que a gestão da mudança seja capaz de influenciar as pessoas para utilizarem as informações da melhor forma possível (NUDURUPATI et al., 2011). Dados tempestivos são muito importantes porque subsidiam os ajustes necessários no Sistema para que este responda de forma adequada às mudanças do ambiente (MELNYK et al., 2014).

Segundo Bititci et al. (2015), essa capacidade de responder ao meio ambiente de forma apropriada se refere à maturidade do Sistema de Avaliação de Desempenho. Assim, quanto maior o nível de maturidade do Sistema, melhor desempenho a organização terá frente às constantes mudanças do meio ambiente. Os modelos de maturidade adicionam valor na prática por meio de uma produção mais rápida dos resultados da avaliação, com revisão das práticas mais eficientes, e reforçam a aprendizagem organizacional (BITITCI et al. 2015).

\subsection{Revisão da literatura sobre Avaliação de Desempenho de Recursos Humanos no setor público}

Nos anos 1980, muitas organizações se tornaram mais interessadas em indicadores de processos e operações que foram incluídos nos Sistemas de Avaliação e Controle (TER BOGT, 2003) para assegurar que os resultados finais esperados pelas organizações poderiam ser alcançados (AZMI, 2010).

Selden et al. (2000) apontam, com base em estudos da década de 1990, que a pesquisa sobre gestão de Recursos Humanos (RH) se divide em três grandes categorias:

1. Foco nas melhores práticas de gestão de RH ou benchmarks de organizações de alto desempenho.

2. Foco nos efeitos de desempenho de práticas específicas de gestão de RH, como treinamento. 
3. Foco em uma perspectiva mais estratégica para examinar a influência das práticas de gestão de RH nos resultados organizacionais.

O terceiro foco, referente ao controle de resultados, teve especial ênfase no setor público com a Nova Gestão Pública e outras reformas convergentes sobre o desempenho e prestação de contas de serviços públicos (TER BOGT, 2003; FRENCH, GOODMAN, 2012; VAN RINSUM, VERBEETEN, 2012; SONGSTAD et al., 2012; VERMEEREN, 2017). Nesse sentido, a gestão de Recursos Humanos deixa de ter uma perspectiva operacional e passa a ter uma perspectiva estratégica, com o objetivo de aumentar a produtividade e eficácia da força de trabalho e, consequentemente, da organização como um todo (DALEY, VASU, 2005; FRENCH, GOODMAN, 2012).

A gestão estratégica de Recursos Humanos se refere a práticas para melhorar a produtividade dos funcionários e a capacidade das organizações de atingir sua missão (DALEY, VASU, 2005), integrando o uso de práticas de pessoal no planejamento estratégico (DALEY, VASU, 2005; MELTON, MEIER, 2017).

A utilização de ferramentas e abordagens do setor privado visa colaborar com essa abordagem estratégica da gestão de Recursos Humanos na gestão pública (FRENCH, GOODMAN, 2012). Assim, entre as reformas na gestão pública, está a introdução de práticas de Recursos Humanos do setor privado (ABU-DOLEH, WEIR, 2007; CONWAY et al., 2016; TANWIR, CHAUDHRY, 2016), tais como Avaliação de Desempenho (FRENCH, GOODMAN, 2012), relacionada ao conceito de melhorar o desempenho e desenvolvimento de pessoas, embora continue sendo usada de forma variada pelas organizações (COOK, CROSSMAN, 2004).

O capital humano foi reconhecido como um componente importante no desempenho organizacional (DALEY, VASU, 2005; AMIN et al., 2014; SRIVASTAVA, DHAR, 2016; MELTON, MEIER, 2017). Pesquisas mostram que, quando as organizações empregam práticas de pessoal como escadas de carreira internas, Sistemas formais de treinamento, Avaliação de Desempenho orientada por resultados, participação de funcionários, empregos definidos e remuneração baseada em desempenho, elas são mais capazes de alcançar seus objetivos (DALEY, VASU, 2005). Essas atividades têm sido referidas como práticas de Recursos Humanos de alto desempenho (MOSTAFA, GOULD-WILLIAMS, BOTTOMLEY, 2015). Além disso, French e Goodman (2012) identificaram, por meio de um estudo empírico, que os gestores de Recursos Humanos reconhecem o uso de Avaliações de Desempenho e medição de desempenho como as funções e atividades mais importantes da gestão de Recursos Humanos.

Todavia, a aplicação das reformas no setor público está sendo cautelosa, ainda existindo muitas práticas de gestão de Recursos Humanos tradicionais como escalas de classificação, especialmente no âmbito local, em detrimento de técnicas mais recentes, como 360 Graus, Avaliação pelos Pares e Avaliações por Subordinados (FRENCH, GOODMAN, 2012). Mudanças nesses Sistemas costumam ser lentas devido ao ambiente burocrático e político do setor público (SELDEN et al., 2000; TANWIR, CHAUDHRY, 2016).

Vermeeren (2017) também salienta que, até agora, as organizações do setor público têm recebido pouca atenção na pesquisa sobre gestão de Recursos Humanos e Desempenho. Há um descontentamento generalizado com Sistemas de Avaliação de Desempenho (COOK, CROSSMAN, 2004), exemplificado pelo estudo empírico de Tanwir e Chaudhry (2016) no caso do Sistema de Avaliação de Desempenho utilizado no setor público do Paquistão.

Para capturar a geração de valor decorrente da interação de políticas e práticas de gestão de Recursos Humanos, é necessário empregar métodos que modelem os entendimentos de especialistas de como os componentes de um Sistema de Gerenciamento de Recursos Humanos interagem entre si e criam mais capacidade interna para gerenciar (SELDEN et al., 2000). Essa 
abordagem está relacionada ao entendimento da Avaliação de Desempenho como um Sistema, que visa analisar a organização de forma holística. Assim, um Sistema de Avaliação de Desempenho é um elemento central da gestão de Recursos Humanos e se refere a um processo composto por partes interligadas a fim de avaliar o desempenho do trabalho para subsidiar a tomada de decião e melhorar o desempenho organizacional (MAKHUBELA, BOTHA, SWANEPOEL, 2016).

Já Vermeeren (2017) [20] salienta que atualmente a pesquisa de gestão de Recursos Humanos enfatiza práticas na análise dos efeitos de gestão no empregado e resultados organizacionais (abordagem do Sistema) em vez de se concentrar no impacto das práticas de recursos humanos individuais (abordagem instrumental). Dessa forma, Vermeeren (2017) propõe que o Sistema de Recursos Humanos seja dividido em três componentes: capacidade de reforço, práticas de Recursos Humanos de reforço de oportunidade e motivação.

Em relação à motivação, Verbeeten (2008) deixou claro que os efeitos comportamentais das práticas de gestão de Desempenho são tão importantes quanto os efeitos econômicos nas organizações do setor público. Hailesilasie (2009) salienta que o desempenho do funcionário depende do comportamento individual (motivação, capacidade e percepção de papel) e em grupo.

Além disso, grande parte da investigação sobre Avaliação de Desempenho se concentra no avaliador e na confiabilidade do instrumento e validade em vez de examinar as opiniões dos envolvidos para que esse Sistema seja reconhecido como justo (COOK, CROSSMAN, 2004). O conceito de justiça dentro das organizações está ligado à motivação, isto é, para motivar as pessoas a trabalhar em direção das metas estabelecidas, esperando recompensas justas (COOK, CROSSMAN, 2004).

Vermeeren (2017) também estudou o relacionamento entre justiça, eficiência, eficácia e gestão de Recursos Humanos e mencionou que uma força de trabalho bem motivada e qualificada é crucial para o sucesso da prestação de serviços públicos. Manolopoulos (2008) concluiu, por meio de um estudo de caso em três estatais da Grécia, que percepções de remuneração justa e com mais segurança no emprego são as principais preocupações relacionadas à motivação extrínseca na gestão pública.

Para o alcance desse melhor desempenho no setor público, muitos municípios holandeses têm mudado suas estruturas de organização, principalmente a partir de 1990, por meio da descentralização em unidades mais ou menos independentes que deveriam realizar acordos de desempenho, tomando como exemplo o gerenciamento de contratos (TER BOGT, 2003). Um contrato de desenvolvimento de desempenho é o processo de estabelecer metas de desempenho pessoal para o ano de referência (COOK, CROSSMAN, 2004). Já Blackman, Buick e O'Donnell (2017) argumentaram que essa abordagem de acordos de desempenho estimula um foco de curto prazo e não estimula modificações habituais na organização, que são necessárias para permitir um alto desempenho a longo prazo.

\section{METODOLOGIA}

\subsection{Enquadramento Metodológico}

Esta pesquisa possui caráter exploratório e descritivo, sendo norteada pela abordagem qualitativa, pois visa analisar um Portfólio Bibliográfico (representativo de um fragmento da literatura) por meio da interpretação dos autores para gerar conhecimento sobre o tema. A coleta de dados é feita por meio de fontes primária e secundária: no primeiro caso, por se tratar da análise interpretativa dos autores acerca do conteúdo dos artigos selecionados; e, no segundo, por se tratar da coleta de variáveis dos artigos científicos selecionados (RICHARDSON, 1999). 
O instrumento de intervenção que orientará o alcance do objetivo de pesquisa é o Knowledge Development Process-Constructivist (ProKnow-C) (DUTRA et al., 2015; VALMORBIDA, CARDOSO, ENSSLIN, 2015; MATOS, ENSSLIN, ENSSLIN, 2019), cuja operacionalização ocorre por meio das etapas: Seleção do Portfólio Bibliográfico (PB), Análise Bibliométrica, Análise Sistêmica e Pergunta de Pesquisa (THIEL, ENSSLIN, ENSSLIN, 2017; VALMORBIDA, ENSSLIN, 2017). Este artigo se propõe a elaborar as etapas de seleção do Portfólio Bibliográfico, da Análise Bibliométrica e Pergunta de Pesquisa para gerar contribuições para o avanço da área.

\subsection{Procedimento para coleta dos dados}

Inicia-se a seleção do Portfólio Bibliográfico (PB) com a definição dos eixos, das palavras-chave que dão origem ao(s) comando(s) de busca e das bases de dados. O Quadro 5 apresenta as informações utilizadas.

Quadro 5 - Eixos, palavras-chave e comandos de busca

\begin{tabular}{|c|c|c|}
\hline Eixos & Palavras-chave & Comandos de busca de cada base de dados \\
\hline \multicolumn{3}{|l|}{ COMANDO 1} \\
\hline 1.1 & evaluat $*, \quad$ measur*, & 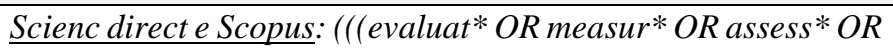 \\
\hline performance & assess $*, \quad$ appraisal, & appraisal OR manag* ${ }^{*}$ OR indicat $*$ ) AND performance) AND \\
\hline evaluation & $\begin{array}{l}\text { manag*, indicat* }{ }^{*} \text { AND } \\
\text { performance }\end{array}$ & $\begin{array}{l}\text { (\{public sector\} OR \{public administration\} OR \{government }\}) \\
\text { AND (servant* OR employee* OR people OR person OR } \\
\text { professional* OR }\{\text { human resource }\} \text { OR }\{\text { human resources }\}))\end{array}$ \\
\hline $\begin{array}{l}1.2 \text { public } \\
\text { sector }\end{array}$ & $\begin{array}{l}\text { public sector, public } \\
\text { administrat*, } \\
\text { government }\end{array}$ & $\begin{array}{l}\text { Web of Science: (( (evaluat* OR measur* OR assess* OR } \\
\text { appraisal OR manag* OR indicat*) AND performance) AND } \\
\text { ("public sector" OR "public administration" OR government) }\end{array}$ \\
\hline $\begin{array}{l}1.3 \text { human } \\
\text { resource }\end{array}$ & $\begin{array}{l}\text { human resource, servant, } \\
\text { person, employee, } \\
\text { people, professional }\end{array}$ & $\begin{array}{l}\text { AND (servant* OR employee* } \text { OR people OR person } O R \\
\left.\text { professional* OR "human resource }{ }^{* \prime \prime}\right) \text { ) }\end{array}$ \\
\hline \multicolumn{3}{|l|}{ COMANDO 2} \\
\hline $\begin{array}{l}2.1 \text { performance } \\
\text { evaluation }\end{array}$ & 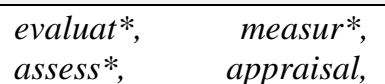 & $\begin{array}{l}\text { Scienc directe Scopus: } \\
\text { appraisal OR manag } * \text { OR indicat } *) \text { AND performance) AND }\end{array}$ \\
\hline & $\begin{array}{l}\text { manag*, indicat* }{ }^{*} \text { AND } \\
\text { performance }\end{array}$ & $\begin{array}{l}\text { (\{government employees\} OR \{government employee\} OR } \\
\text { \{civil service\} OR \{civil services\} OR \{civil servant\} OR \{civil } \\
\text { servants\} OR \{public servant\} OR \{public servants\})) } \\
\text { Web of Science: (( } \text { evaluat }^{*} \text { OR measur* OR assess } * \text { OR } \\
\text { appraisal OR manag* OR indicat*) AND performance) AND }\end{array}$ \\
\hline 2.2 civil service & $\begin{array}{l}\text { government employee, } \\
\text { civil service, civil } \\
\text { servant, public servant }\end{array}$ & $\begin{array}{l}\text { ("government employee*" OR "civil service*" OR "civil } \\
\text { servant*" OR "public servant*")) }\end{array}$ \\
\hline
\end{tabular}

Fonte: Elaborado pelos autores.

Os comandos de busca utilizados para selecionar artigos sobre o tema são estes: (i) o Comando 1 que utiliza três eixos para buscar temas relacionados às palavras-chave: Avaliação de Desempenho, setor público e Recursos Humanos; e (ii) o Comando 2 que utiliza dois eixos para buscar temas relacionados às palavras-chave: Avaliação de Desempenho e servidores públicos. O limite temporal da busca por artigos científicos teve por base o entendimento de que os últimos anos reúnem um fragmento representativo da literatura sobre o tema.

Assim, a busca de artigos, em inglês, publicados a partir de 2000 que continham os dois comandos de busca no título, resumo ou palavra-chave nas bases de dados da Capes (Scopus, Web of Science e Science Direct), foi feita em 31 de março de 2018, resultando num Portfólio bruto de 6.184 artigos. Estes foram exportados para o software EndNote e excluídas 2.688 publicações duplicadas diretamente pelo software e 33 publicações em conferências, livros e 
capítulos de livros, obtendo, ao final dessa primeira filtragem, 3.463 artigos. Estes foram examinados conforme o título e constatou-se que 3.353 apresentavam títulos claramente desalinhados. Os 110 artigos com título alinhado passaram a ser analisados pelo teste de representatividade científica. Nessa investigação, os 43 artigos mais citados representam 95\% do total de citações, com 16 ou mais citações; e os 67 artigos restantes apresentam menos de 16 citações, formando um repositório com artigos potencialmente relevantes. Dos 43 artigos com título alinhado e com reconhecimento científico, 25 deles possuem o resumo alinhado com o tema, cujos 57 autores, entre autores e coautores, formaram o Banco de Autores (BA). Os 67 artigos com título alinhado, mas sem atendimento à representatividade científica, foram divididos em dois grupos: o grupo dos artigos recentes (publicados em 2016, 2017 e 2018) e o grupo dos antigos. O grupo dos recente totalizou 25 artigos e dos antigos totalizou 42 antigos. Desses 42, três artigos foram escritos por pelo menos um dos autores integrante do BA, e, nesse caso, estes três artigos foram separados para que seus resumos fossem lidos. Assim, passou-se à leitura dos 25 artigos recentes e dos três escrito pelos autores integrantes do BA. Dos 28 artigos, constatou-se que 12 apresentaram resumo alinhado com o tema.

Na sequência, fez-se a leitura integral desses 37 artigos, dos quais cinco não estavam disponíveis na íntegra e 11 estavam desalinhados com o tema. Assim, 21 artigos foram selecionados para compor o Portfólio Bibliográfico (PB) final. O resumo da etapa da Filtragem desse Portfólio é apresentado na Figura 2:

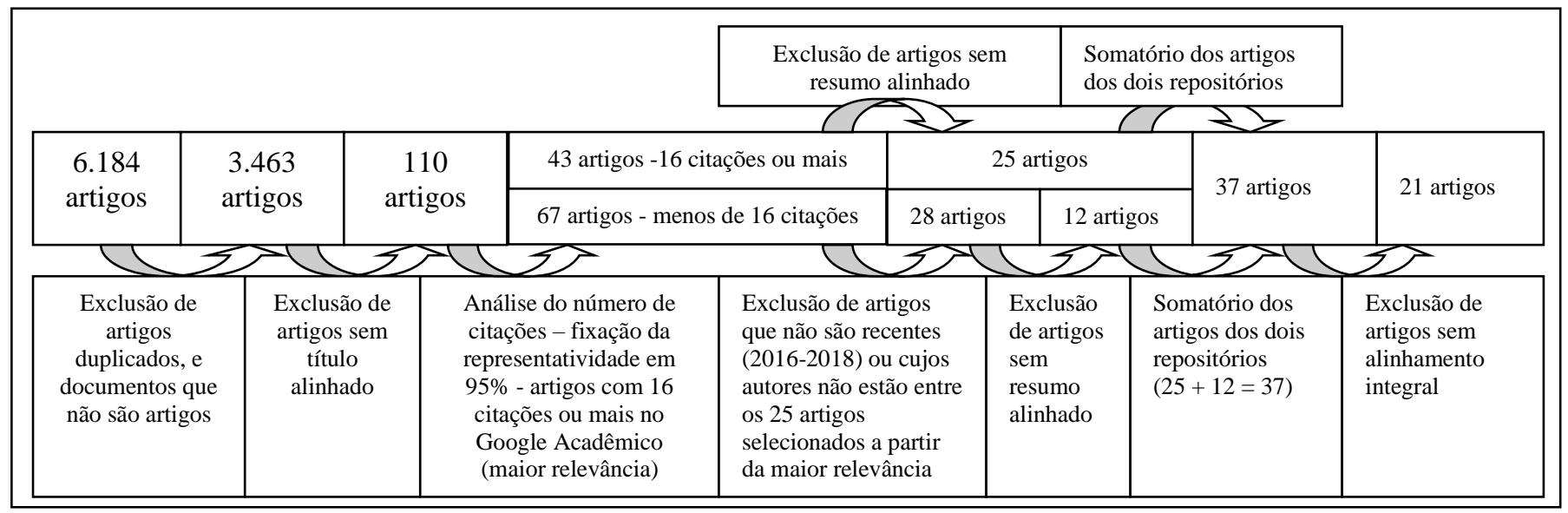

Figura 2 - Processo de Filtragem do Portfólio Bruto

Fonte: Elaborada pelos autores com base na etapa de Filtragem do ProKnow-C.

Com base nos procedimentos do ProKnow-C, foi possível selecionar 21 artigos disponíveis gratuitamente que compõem o Portfólio Bibliográfico (PB), objeto de análise da presente pesquisa, sendo os dados que darão suporte aos achados desta pesquisa. Esses artigos estão listados na seção das Referências com um número sequencial de 1 até 21 entre [ ] ao final.

Salienta-se que, para fortalecer a precisão da Seleção do PB, um dos autores, com experiência em utilizar o ProKnow-C, atuou como member checking, conferindo o desenvolvimento e os resultados de todas as subetapas feitas, conforme sugerido por Creswell (2014). Nos momentos em que surgiram dúvidas ou divergência nos resultados de cada subetapa, os autores debateram os pontos problemáticos a fim de identificarem alinhamentos com as delimitações por eles estabelecidas.

\subsection{Procedimento para análise dos dados}


O procedimento para análise dos dados na etapa da Análise Bibliométrica abrange a análise de características básicas e de avançadas do PB (THIEL, ENSSLIN, ENSSLIN, 2017).

As características básicas referem-se: (i) à evolução das pesquisas ao longo dos anos; (ii) às ferramentas utilizadas; (iii) às redes de coautoria; (iv) às redes de instituições dos autores; e (v) à distribuição geográfica das pesquisas.

As características avançadas baseiam-se em aportes teóricos detalhados na Seção 2.1, consistindo na análise do Portfólio com base na:

(i) investigação do uso de indicadores na perspectiva de um Sistema, que pode ser examinado em três níveis: as medidas de desempenho individuais, o conjunto de medidas de desempenho e a relação entre esse Sistema e o ambiente no qual opera, segundo manifestações de Neely, Gregory e Platts (1995); essa análise também visa à elaboração de uma listagem dos principais indicadores adotados internacionalmente, com base na aglutinação dos indicadores apontados por mais de um artigo do Portfólio;

(ii) observância dos artigos em relação ao ciclo de vida de um Sistema de Avaliação de Desempenho, proposto por Bourne et al. (2000), que envolve as etapas de design, implementação, uso e revisão;

(iii) investigação da função da Avaliação de Desempenho na gestão pública a que é dada mais ênfase em cada artigo, quais sejam: avaliar, controlar, orçar, motivar, promover, celebrar, aprender e melhorar, segundo Behn (2003); e

(iv) identificação de falhas dos Sistemas de Avaliação de Desempenho, conforme identificado por Van Camp e Braet (2016).

A análise dessa última característica avançada fornecerá os principais subsídios para identificação e proposta de oportunidades para futuras investigações, conforme descrito na Seção 4.3. O procedimento de member checking realizado na coleta de dados foi também realizado na análise dos dados; entretanto a análise dos dados foi realizada por dois dos autores em separado e o terceiro autor conferiu as informações para evitar possíveis discrepâncias nos resultados.

\section{RESULTADOS}

\subsection{Análise bibliométrica: características básicas}

Inicialmente, destaca-se que todos os 21 artigos que compõem o PB referem-se a pesquisas empíricas. Em relação às variáveis básicas a serem analisadas nesses artigos, a primeira se refere ao lapso temporal de publicação dos artigos, que abrange o período de 2000 a 2017, conforme Quadro 6.

Quadro 6 - Evolução das pesquisas ao longo dos anos

\begin{tabular}{ll}
\hline \multicolumn{1}{c}{ Ano de publicação do artigo } & \multicolumn{1}{c}{ Foco } \\
\hline 2000,2016 & Desenvolvimento de um sistema de avaliação de desempenho \\
2003 & Identificação de critérios e estilos de avaliação de desempenho \\
$2004,2012,2016$ & Nível de satisfação com o sistema \\
$2005,2008,2014,2015,2017$ & $\begin{array}{l}\text { Impacto de práticas de gestão de RH no desempenho } \\
\text { Investigação se o sistema de avaliação no setor público está } \\
\text { atendendo as suas funções }\end{array}$ \\
\hline
\end{tabular}




\begin{tabular}{ll}
$2008,2009,2012,2016,2017$ & Análise de variáveis que afetam o desempenho \\
2010 & Grau de utilização de práticas de gestão de RH \\
2012 & Importância das funções e atividades para prática de RH \\
2016 & $\begin{array}{l}\text { Impacto do sistema de gestão de desempenho no bem-estar dos } \\
\text { funcionários } \\
2017\end{array}$ \\
$\begin{array}{l}\text { Exposição de motivos do fracasso do gerenciamento do } \\
\text { desempenho de funcionários }\end{array}$ \\
\hline
\end{tabular}

Fonte: Elaborado pelos autores.

A análise temporal do Portfólio mostra que algumas pesquisas são convergentes, enquanto outras possuem um enfoque mais isolado, conforme Quadro 6.

O artigo que inicia essa série, de autoria de Selden et al. (2000), trata do desenvolvimento de um método para avaliar os governos estaduais dos Estados Unidos e compara, de forma abrangente, os Sistemas de gestão de RH, apresentando um ranking de desempenho. O artigo de Tanwir e Chaudhry (2016) também apresenta um instrumento para medir com mais precisão o desempenho de funcionários públicos do Paquistão, composto por um formulário com metas mais objetivas. Esses dois artigos são casos isolados, já que a maior parte dos artigos estabeleceu implicações de práticas e percepções associadas ao desempenho ou analisou variáveis que afetam o desempenho de Recursos Humanos em organizações públicas.

Assim, destacam-se estudos relacionados ao impacto de práticas de gestão de RH no desempenho, conforme mencionado por Selden et al. (2000) [1] como a última etapa evolutiva da pesquisa sobre gestão de RH na década de 1990. Esse enfoque estratégico da gestão de RH está ligado à Nova Gestão Pública, citada por oito artigos publicados no período de 2003 a 2017, cujo objetivo é a gestão baseada em resultados, mostrando a importância que passou a ser dada ao desempenho do setor público, tanto para aumentar a eficiência e o desempenho dos funcionários, quanto para prestar contas dos resultados aos stakeholders.

Destacam-se cinco artigos que analisam variáveis que afetam o desempenho, sendo que os artigos de Manolopoulos (2008), Hailesilasie (2009), Van Rinsum, Verbeeten (2012) analisam a relação entre a variável Motivação e o Desempenho; e o artigo de Srivastava e Dhar (2016) analisa, entre outras, a variável Comprometimento Organizacional que desempenha um papel importante na motivação dos empregados.

Esses entendimentos convergem com Vermeeren (2017), que salienta que atualmente a pesquisa de gestão de Recursos Humanos enfatiza práticas na análise dos efeitos de gestão no empregado e resultados organizacionais (abordagem do Sistema).

Percebe-se que outras pesquisas analisam o nível de satisfação com o Sistema de Gestão de Desempenho e o impacto do Sistema no bem-estar dos funcionários. Ou seja, investigam se um Sistema de Avaliação de Desempenho é considerado justo na percepção dos funcionários, pois a equidade do Sistema gera motivação que impacta diretamente no desempenho, a exemplo das pesquisas de Cook, Crossman (2004), Songstad et al. (2012) e Makhubela, Botha, Swanepoel (2016).

Identifica-se, ainda, a tendência de agregar a perspectiva de um maior número de stakeholders nas pesquisas, exemplificada pela ampliação do grupo focal de entrevistados no artigo de Amin et al. (2014) cuja amostra inclui acadêmicos e equipe administrativa de universidades públicas da Malásia, e no artigo de Mostafa, Gould-Williams e Bottomley (2015) que incluiu acadêmicos, administradores, médicos, enfermeiros e farmacêuticos de organizações do setor público no Egito.

A segunda variável básica se refere às ferramentas de pesquisa apontadas no Gráfico 1 . 


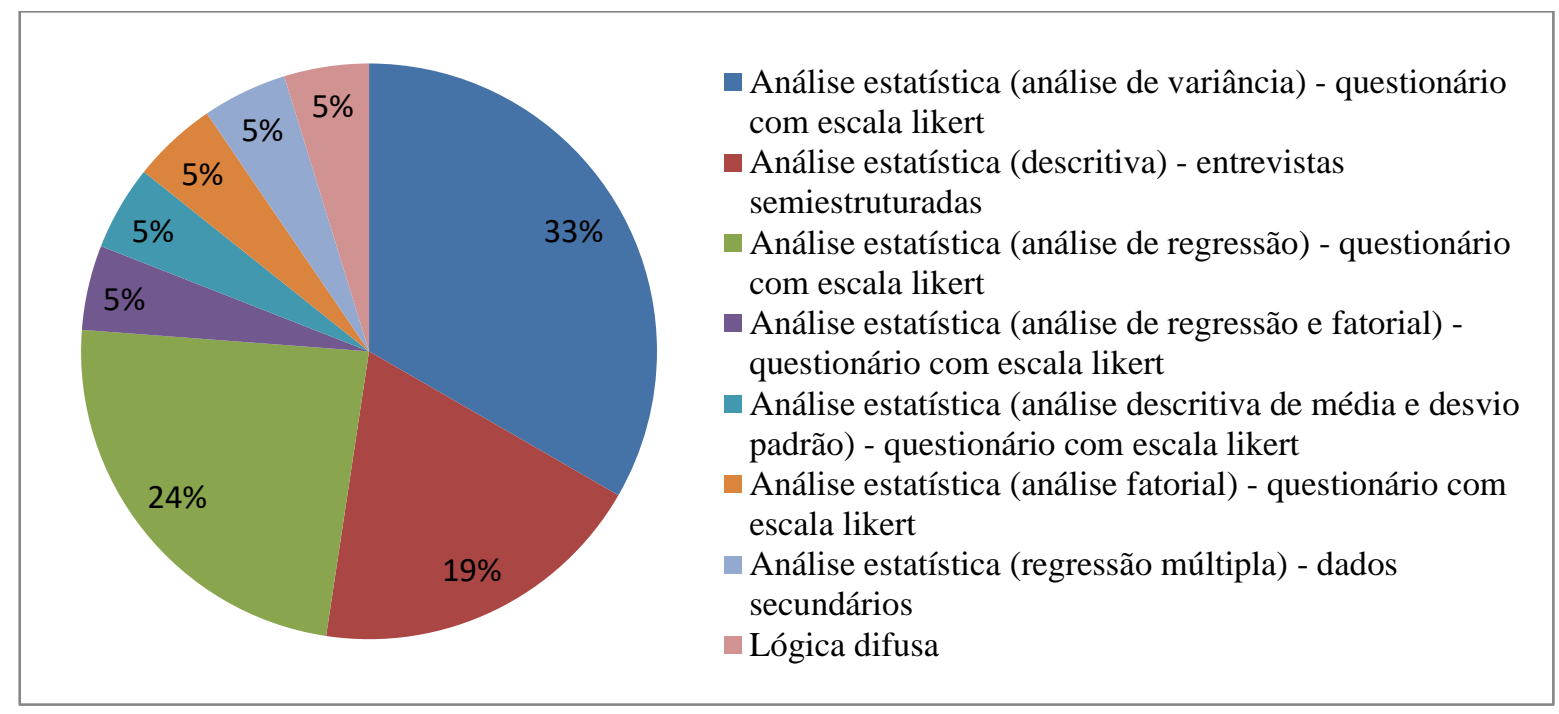

Gráfico 1 - Ferramentas utilizadas nos artigos do Portfólio Fonte: Elaborado pelos autores.

Conforme o Gráfico 1, destaca-se a utilização da modelagem de equações estruturais, que visa analisar simultaneamente múltiplas variáveis, como os métodos de análise de variância, regressão e fatorial ( $72 \%$ dos casos). A utilização dessa metodologia está diretamente relacionada ao desenvolvimento tecnológico de softwares. A coleta de dados dessas pesquisas possui fonte predominantemente primária, por meio da aplicação de questionários aos envolvidos (principalmente funcionários) em organizações públicas, com especial adoção da Escala Likert.

Quatro pesquisas (19\% dos casos) adotam a análise descritiva de entrevistas semiestruturadas, algumas com uso das medidas de média e desvio padrão. Não foi identificada relação entre as ferramentas utilizadas e a época de publicação, pois não houve concentração em anos específicos.

A ferramenta que mais difere do grupo é a Lógica Difusa, utilizada na pesquisa de Selden et al. (2000) para desenvolver um método que captasse os desafios de avaliar o Desempenho da Gestão de Recursos Humanos.

Em relação à análise das variáveis básicas das redes de coautorias e instituições do Portfólio seguem os Gráficos 2 e 3, elaborados por meio do software VOSviewer.

Verifica-se que não há um corpo de conhecimento consolidado sobre o tema, pois os autores e as instituições estão bem dispersos. No caso da rede de coautorias, há quatro grupos principais, mas se trata de autores do mesmo artigo. No caso das instituições, nota-se que há pouca troca de conhecimento.

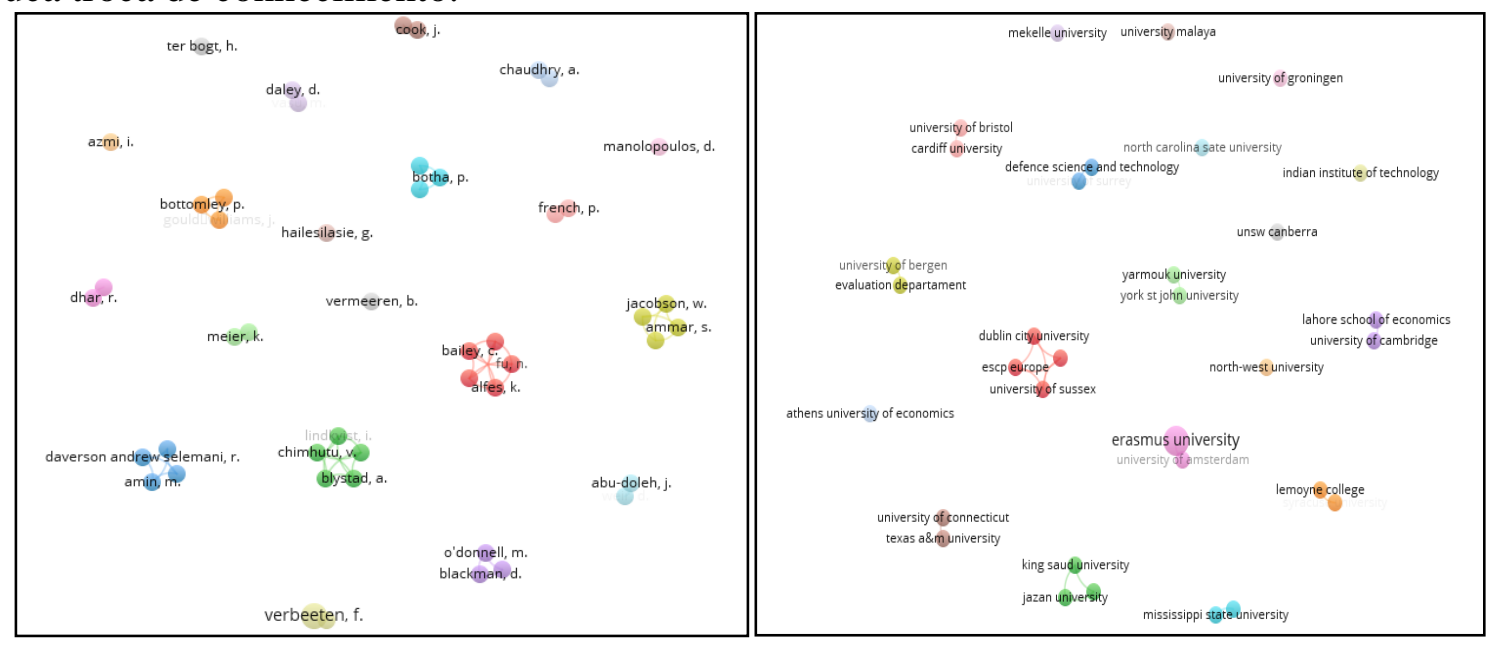


Gráfico 2 - Rede de coautorias

Fonte: Elaborado pelos autores.
Gráfico 3 - Rede de instituições

Fonte: Elaborado pelos autores.

Cabe mencionar que, em relação ao Portfólio, apenas o autor Verbeeten tem mais de um artigo, um de 2008 e outro de 2012 (coautor), vinculados a Erasmus University, sendo que o de 2008 teve o maior número de citações no Google Acadêmico entre todos do Portfólio (273 citações, em 14 de abril de 2018). Verbeeten é professor de Contabilidade, na Faculdade de Economia, da Universidade de Utrecht, professor de Controle de Gestão, na Vrije Universiteit Amsterdam, e membro do conselho editorial do Journal of Management Control. Ele é coorganizador da conferência European Institute for Advanced Studies in Management EIASM, no campo de Avaliação de Desempenho e Controle de Gerenciamento. Embora Verbeeten pesquise sobre o tema, ele também concentra esforços em outras áreas voltadas ao Desempenho Financeiro.

Assim, verifica-se que a autora Selden se destaca mais nessa área específica do conhecimento, pois foi citada por outros cinco artigos do Portfólio final. Selden é professora associada de Administração, no Lynchburg College, nos Estados Unidos. Ela foi responsável por liderar a equipe acadêmica que classificou os Sistemas de Gerenciamento de Recursos Humanos dos governos estaduais nos Estados Unidos. Atua no Conselho Consultivo Acadêmico de Parceria para o Serviço Público e no Comitê Executivo de Gestão de Recursos Humanos da Sociedade Americana de Administração Pública. Suas pesquisas incluem gestão pública, gestão de Recursos Humanos e eficácia da gestão sem fins lucrativos.

A quinta variável básica se refere à distribuição geográfica das 21 pesquisas e observase que elas foram feitas em países dos cinco continentes, relacionados, a seguir, por ordem decrescente de concentração de artigos: Europa (33\%), Ásia (24\%), África (19\%), América $(19 \%)$ e Oceania (5\%). A maior concentração das pesquisas, na Europa, converge para o forte desenvolvimento de pesquisas desse continente na área gerencial. Os países mais pesquisados do Portfólio foram a Holanda (quatro artigos) e os Estados Unidos (quatro artigos).

\subsection{Análise bibliométrica: características avançadas}

A primeira variável avançada se refere à identificação do uso de indicadores na perspectiva de um Sistema que pode ser examinado em três níveis (NEELY, GREGORY, PLATTS, 1995), conforme Figura 3:

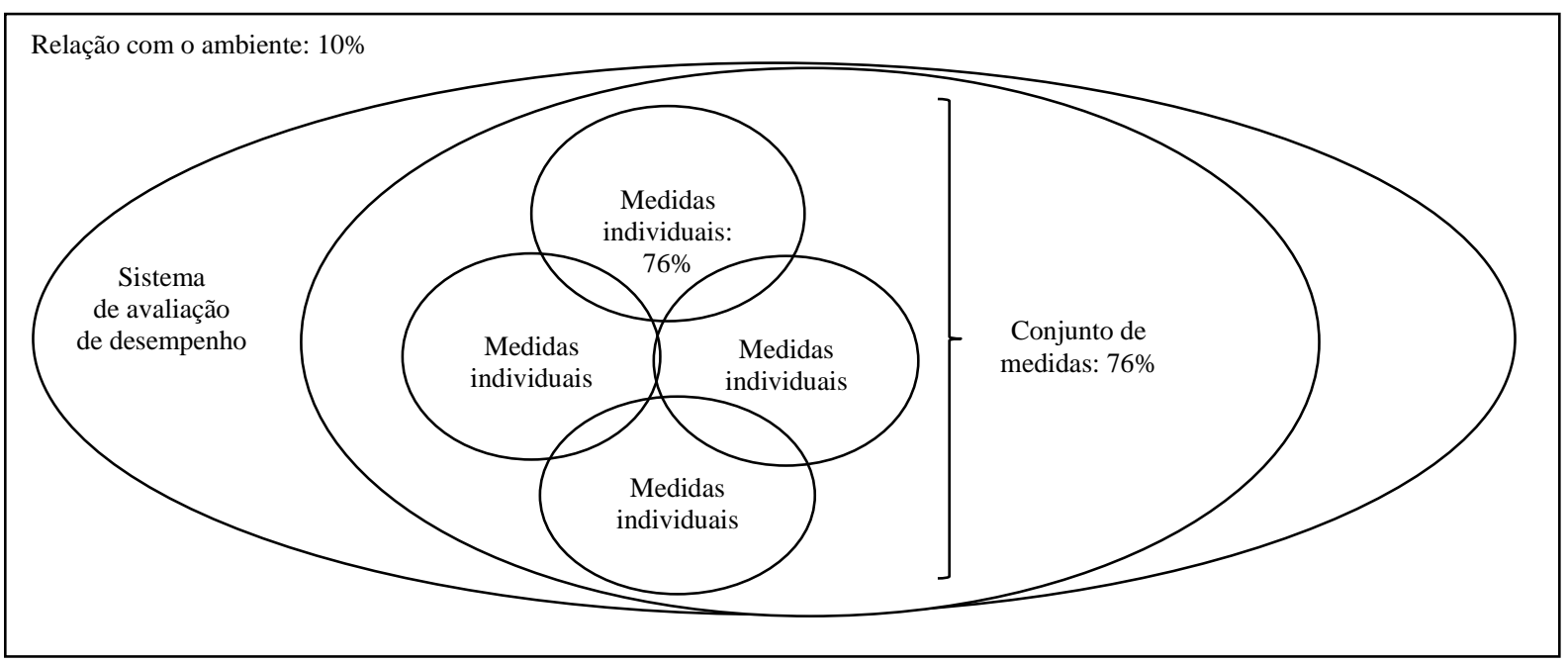

Figura 3: Análise das pesquisas quanto ao uso de indicadores de Desempenho Fonte: Elaborada pelos autores, com base em Neely, Gregory, Platts, 1995. 
De acordo com a Figura 3, a maior parte das pesquisas (76\%) apresenta indicadores de desempenho individuais, bem como um conjunto de indicadores de desempenho (76\%). Todavia, na maior parte das pesquisas, não se percebe se há relação entre o Sistema de Avaliação de Desempenho e o ambiente ou não se aplica. Há dois artigos nos quais essa relação com o ambiente interno é evidenciada, representando $10 \%$ do Portfólio. São as pesquisas de Selden et al. (2000) e Tanwir e Chaudhry (2016), nas quais são desenvolvidos Sistemas de Avaliação de Desempenho. Logo, nenhuma pesquisa faz relação com o ambiente externo.

Quanto aos indicadores apontados nos artigos, a relação é apresentada no Quadro 7:

Quadro 7 - Principais indicadores citados nos artigos

\begin{tabular}{|c|c|}
\hline Termo genérico & Exemplos de termos utilizados \\
\hline Recrutamento & Recrutamento/Recrutamento e seleção \\
\hline $\begin{array}{l}\text { Descrição do } \\
\text { trabalho }\end{array}$ & $\begin{array}{l}\text { Descrição de emprego/Definição de trabalho/Atribuições/Design de trabalho e } \\
\text { processo }\end{array}$ \\
\hline Promoção & $\begin{array}{l}\text { Carreira/Promoção/Oportunidade para crescimento/Oportunidade de assumir } \\
\text { responsabilidades/Potencial de realizar uma função mais elevada }\end{array}$ \\
\hline Treinamento & Treinamento/Treinamento e desenvolvimento/Capacitação \\
\hline $\begin{array}{l}\text { Colaboração e } \\
\text { comunicação }\end{array}$ & $\begin{array}{l}\text { Comunicação e cooperação no ambiente de trabalho/comunicação/Compartilhamento } \\
\text { de informações práticas/Trabalho e equipe de autonomia e descentralização/ Relações } \\
\text { de trabalho }\end{array}$ \\
\hline Participação & $\begin{array}{l}\text { Participação/participação dos funcionários/participação dos trabalhadores nas } \\
\text { tomadas de decisões }\end{array}$ \\
\hline Reconhecimento & Reconhecimento de desempenho/Reconhecimento para o trabalho/Reconhecimento \\
\hline $\begin{array}{l}\text { Segurança do } \\
\text { emprego/Retenção }\end{array}$ & Segurança do emprego/Retenção/Rescisão/Demissão \\
\hline Recompensa & $\begin{array}{l}\text { Recompensa/Pagamento/Salário/Bônus/Incentivos remuneratórios/Pagamento por } \\
\text { desempenho }\end{array}$ \\
\hline
\end{tabular}

Fonte: Elaborado pelos autores.

Assim, conforme o Quadro 7, são identificados nove principais indicadores de desempenho citados nos artigos, com base na aglutinação das nomenclaturas utilizadas. Os principais indicadores citados são treinamento e recompensa, com destaque para Pagamento por Desempenho. Como exemplo, Songstad et al. (2012) examinam um Sistema de Pagamento por Desempenho na Tanzânia; Hailesilasie (2009) descreve que a Etiópia busca um Sistema de Remuneração baseado no desempenho; e French e Goodman (2012) apontam que esse tipo de pagamento tende a aumentar.

Quanto ao alinhamento dos indicadores com a estratégia, apenas três pesquisas demonstram essa relação. Essa falta de alinhamento com a estratégia é uma falha no âmbito de gestão que deve ser sanada para que o Sistema de Avaliação de Desempenho alcance o objetivo da melhoria contínua da gestão, pois indicadores desalinhados podem prejudicar a organização e trazer efeitos disfuncionais (VAN CAMP, BRAET, 2016).

Embora a maior parte dos artigos aponte indicadores de desempenho, esses artigos não chegam a mensurar o desempenho, salvo o de Selden et al. (2000) que, além de mensurar o desempenho de organizações de diferentes estados, também compara os resultados por meio de um ranking. Percebe-se, de forma geral, que as pesquisas analisam implicações de práticas e percepções associadas ao Desempenho de Recursos Humanos em organizações públicas, mas sem considerar o ambiente, a estratégia da organização e as necessidades de todos os stakeholders, dificultando a análise no âmbito da Teoria Geral de Sistemas que, para Choong (2014), deve subsidiar esses estudos. 
Parece que as pesquisas ainda estão na etapa de identificar as medidas que devem ser usadas, sem uma análise mais aprofundada do porquê essas medidas são usadas, sendo questões que, segundo Lebas (1995), devem nortear a construção de um Sistema de Avaliação de Desempenho para refletir as relações de causa e efeito e apoiar a tomada de decisões.

Essa análise é consistente com a segunda variável avançada, que se refere ao alcance dos artigos em relação às etapas do ciclo de vida de um Sistema de Avaliação de Desempenho: design, implementação, uso e revisão (BOURNE et al., 2000), conforme Gráfico 4.

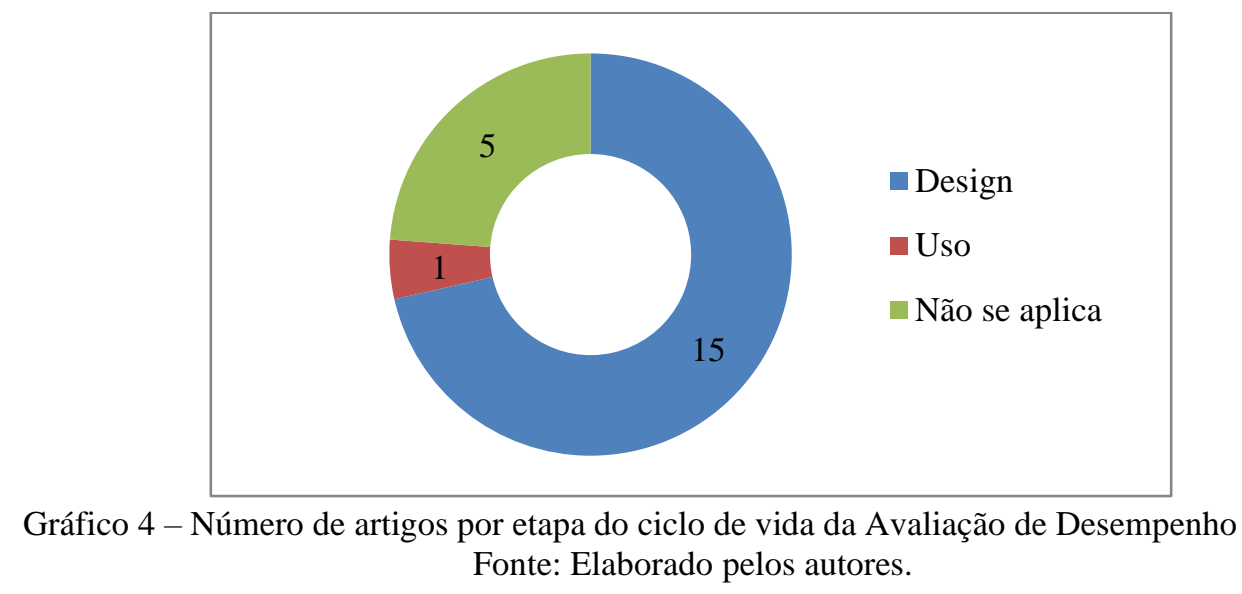

De acordo com o Gráfico 4, a maior parte dos artigos (15) alcança apenas a primeira etapa do ciclo, que é o design das medidas de desempenho, ao passo que um artigo desenvolve o Sistema até a etapa do uso. Ademais, essa análise não é aplicável a cinco artigos. Conclui-se assim, de forma análoga a Bourne et al. (2000), que as pesquisas sobre Avaliação de Desempenho se concentram apenas nos estágios iniciais, sem estudar a implementação e o acompanhamento dos Sistemas.

Com base na análise de Franco-Santos et al. (2007), percebe-se que as pesquisas se concentram mais nas características do Sistema de Avaliação de Desempenho (especificamente nos indicadores) e nas funções do Sistema, sem analisar os processos necessários para que o Sistema funcione. Dessa forma, ainda que as pesquisas não tenham se aprofundado no desenvolvimento e uso de um Sistema de Avaliação de Desempenho, elas apontam as funções desse Sistema e das práticas de gestão de Recursos Humanos.

Portanto, foi possível desenvolver a terceira variável avançada, cujo objetivo é identificar a função da Avaliação de Desempenho na gestão pública visto que é dada mais ênfase nas pesquisas do Portfólio, quais sejam: avaliar, controlar, orçar, motivar, promover, celebrar, aprender e melhorar (BEHN, 2003). Essa análise é evidenciada no Gráfico 5:

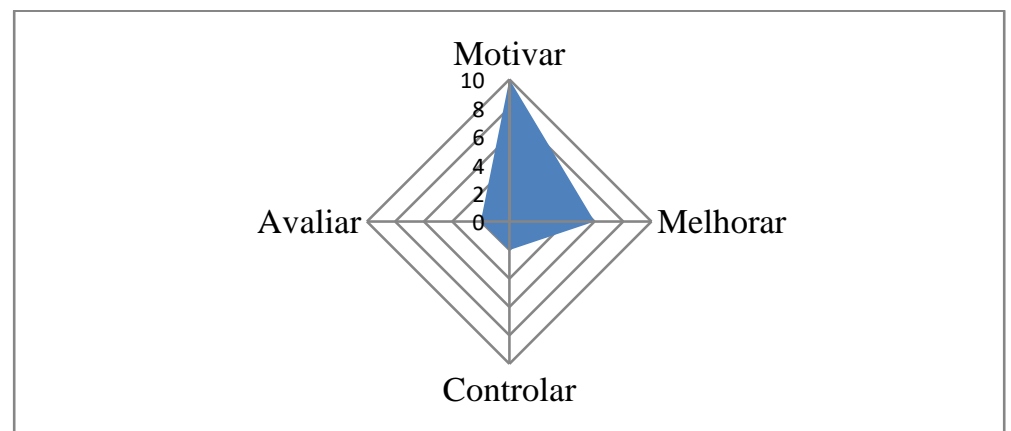

Gráfico 5 - Número de artigos por etapa do ciclo de vida da Avaliação de Desempenho Fonte: Elaborado pelos autores. 
Muitos artigos demonstram a importância da função Motivar para a melhoria do desempenho dos funcionários. Em seguida, destaca-se a função Melhorar, pois essa é a maior finalidade da Avaliação de Desempenho. Aparecem ainda artigos com enfoque na função Controlar, um deles inclusive visando também promover a prestação de contas aos stakeholders. Outros artigos destacaram a função Avaliar. Essa classificação é relevante para perceber que a principal função da Avaliação de Desempenho de Recursos Humanos no setor público, apontada nas pesquisas, é a Motivar.

Pessoas altamente motivadas são correlacionadas a melhores resultados organizacionais (HAILESILASIE, 2009; MELTON, MEIER, 2017; VERMEEREN, 2017). Assim, oportunidades de promoção e segurança no trabalho, bem como programas de treinamento e desenvolvimento podem sinalizar reconhecimento dos empregados a longo prazo, gerando confiança e motivação (MOSTAFA, GOULD-WILLIAMS, BOTTOMLEY, 2015).

A importância da motivação no setor público está ligada ao fato de que os formulários de avaliação, aplicados aos funcionários públicos, não têm critérios tangíveis orientados para o desempenho, a exemplo das avaliações subjetivas utilizadas na burocracia do Paquistão, resultando em desmotivação dos funcionários, pois as transferências e promoções não são baseadas no desempenho e na meritocracia, mas, sim, no alinhamento político (TANWIR, CHAUDHRY, 2016 [18]). A gestão de Desempenho é vista como um evento burocrático anual, na qual os gerentes avaliam superficialmente o desempenho dos subordinados (BLACKMAN, BUICK, O’DONNELL, 2017).

Além disso, a subjetividade nas práticas de Avaliação de Desempenho reduz a clareza da missão percebida e afeta negativamente a confiança dos subordinados em seu supervisor, o que diminui a motivação (VAN RINSUM, VERBEETEN, 2012). Uma forma de combater essa subjetividade é a utilização de metas claras e mensuráveis, que estão positivamente associadas ao desempenho quantitativo e de qualidade, consistente com a Teoria de Definição de Metas (VERBEETEN, 2008).

Além disso, mecanismos de participação dos funcionários podem aumentar o engajamento e motivação para contrabalançar as demandas de um Sistema de Gerenciamento de Desempenho (CONWAY et al., 2016). Cook e Crossman (2004) alertam que é necessário considerar as opiniões dos envolvidos para que esse Sistema seja validado e reconhecido como justo. Como exemplo, cita-se que, devido à falta de participação dos funcionários no processo de Avaliação de Desempenho e na definição de metas, bem como a falta de sessões regulares de feedback de desempenho, o Sistema de Avaliação de uma organização pública da África do Sul foi considerado ineficaz e injusto pelos funcionários (MAKHUBELA, BOTHA, SWANEPOEL, 2016).

Abu-Doleh e Weir (2007) também destacam que os Sistemas empregados precisam atender melhor às suas funções e precisam incluir outro avaliador, além do gerente, nesse processo de avaliação. Acerca disso, Srivastava e Dhar (2016) afirmam que os supervisores devem utilizar a Avaliação 360 Graus para avaliar o desempenho de seus subordinados e propiciar um ambiente de trabalho harmonioso. Em síntese, enquanto o funcionário não for avaliado com precisão e de forma justa, dificilmente ele se sentirá valorizado e motivado na organização.

Ante o exposto, foi possível desenvolver a quarta variável avançada, referente à identificação nos artigos do Portfólio de falhas dos Sistemas de Avaliação de Desempenho nos três níveis, conforme Van Camp e Braet (2016): falta de definição clara, falta de métricas objetivas (nível métrico), falta de feedback e aprendizado, falta de âmbito articulado dos ambientes interno e externo (nível de framework), falta de alinhamento com a estratégia e falta de envolvimento do usuário (no âmbito de gestão).

Essas falhas demonstram que a pesquisa sobre Avaliação de Desempenho de Recursos Humanos no setor público precisa avançar em direção à mensuração e ao 
diagnóstico do desempenho de uma forma holística e integrada. Todavia, essas pesquisas podem estar refletindo a realidade do setor público, que ainda está aquém de uma Avaliação de Desempenho capaz de agregar todos os indicadores necessários e alinhados aos objetivos estratégicos da organização. Isso pode estar relacionado ao atraso na adoção de um Sistema de Avaliação de Desempenho em relação às organizações privadas.

\subsection{Contribuições para o avanço da área}

Com base na quarta variável avançada, referente às falhas do Sistema de Avaliação de Desempenho de Recursos Humanos, foi possível estabelecer oportunidades de pesquisas e desafios para os gestores, conforme Quadro 8.

Quadro 8-Oportunidades de pesquisas e desafios para os gestores

\begin{tabular}{|c|c|c|c|}
\hline Nível & Elemento & $\begin{array}{c}\text { Oportunidades de pesquisas para } \\
\text { teóricos }\end{array}$ & Desafios para gestores \\
\hline \multirow{2}{*}{ Métrico } & $\begin{array}{l}\text { Definição } \\
\text { clara }\end{array}$ & $\begin{array}{l}\text { Avaliar se as medidas empregadas } \\
\text { são claras e compreendidas pelos } \\
\text { funionários da mesma maneira. }\end{array}$ & $\begin{array}{l}\text { Definir medidas claras capazes de } \\
\text { mensurar o real desempenho dos } \\
\text { recursos humanos. }\end{array}$ \\
\hline & $\begin{array}{l}\text { Métricas } \\
\text { objetivas }\end{array}$ & $\begin{array}{l}\text { Analisar se as medidas são objetivas, } \\
\text { sem margens para subjetividade ou } \\
\text { direcionamento político. }\end{array}$ & $\begin{array}{l}\text { Estabelecer medidas objetivas e } \\
\text { desmembrar medidas subjetivas a } \\
\text { um nível objetivo. }\end{array}$ \\
\hline \multirow[b]{2}{*}{ Framework } & $\begin{array}{l}\text { Feedback e } \\
\text { aprendizado }\end{array}$ & $\begin{array}{l}\text { Investigar se os funcionários estão } \\
\text { recebendo feedback acerca de seu } \\
\text { desempenho. }\end{array}$ & $\begin{array}{l}\text { Realizar feedbacks regulares com } \\
\text { os funcionários. }\end{array}$ \\
\hline & $\begin{array}{l}\text { Âmbito } \\
\text { articulado }\end{array}$ & $\begin{array}{l}\text { Destacar a importância da integração } \\
\text { dos efeitos internos e externos na } \\
\text { elaboração de sistemas. }\end{array}$ & $\begin{array}{l}\text { Agregar os stakeholders internos e } \\
\text { externos no processo de avaliação } \\
\text { de desempenho. }\end{array}$ \\
\hline \multirow{2}{*}{ Gestão } & $\begin{array}{l}\text { Alinhamento } \\
\text { com a } \\
\text { estratégia }\end{array}$ & $\begin{array}{l}\text { Expor de forma clara o impacto de } \\
\text { cada métrica para o alcance da } \\
\text { estratégia da gestão de recursos } \\
\text { humanos. }\end{array}$ & $\begin{array}{l}\text { Estabelecer métricas voltadas ao } \\
\text { atendimento da estratégia e da } \\
\text { melhoria contínua da gestão. }\end{array}$ \\
\hline & $\begin{array}{l}\text { Envolvimento } \\
\text { do usuário }\end{array}$ & $\begin{array}{l}\text { Investigar casos em que há } \\
\text { envolvimento dos usuários para } \\
\text { demonstrar se há maior compromisso } \\
\text { com os objetivos da organização. }\end{array}$ & $\begin{array}{l}\text { Envolver os usuários em todo o } \\
\text { processo de um sistema de } \\
\text { avaliação de desempenho para que } \\
\text { ele seja validado pelos envolvidos. }\end{array}$ \\
\hline
\end{tabular}

Fonte: Elaborado pelos autores. Baseado em Van Camp e Braet (2016).

As oportunidades e desafios listados demonstram que muitos elementos precisam ser incorporados nas pesquisas sobre Avaliação de Desempenho de Recursos Humanos no setor público para que essa prática seja capaz de alcançar a melhoria contínua da gestão.

\section{CONCLUSÕES}

O objetivo deste trabalho foi analisar as características das publicações científicas, em língua inglesa, que abordam o tema referente à Avaliação de Desempenho de Recursos Humanos no setor público, para gerar conhecimento e identificar lacunas e possibilidades de contribuições para futuras pesquisas. A ferramenta utilizada foi o Knowledge Development Process-Constructivist (Proknow-C), que possibilitou a seleção de um Portfólio Bibliográfico 
(PB) sobre o tema e é composto por 21 artigos científicos internacionais, com base no qual foi feita a análise bibliométrica para gerar contribuições para o avanço da área.

A análise do PB permitiu a verificação da relação entre a gestão de Recursos Humanos no setor público e a Avaliação de Desempenho (AD). Quanto à análise das características básicas, destaca-se que as pesquisas estão distribuídas por todos os continentes, mas de uma maneira muito dispersa, e não há formação de redes de colaboração entre autores e instituições. A única autora de destaque foi a professora estadunidense Sally Coleman Selden, citada por outros artigos do Portfólio. Quanto às ferramentas utilizadas, destaca-se a Modelagem de Equações Estruturais. Em relação à análise temporal, a maior parte dos artigos estabeleceu implicações de práticas e percepções associadas ao desempenho ou analisou variáveis que afetam o desempenho de Recursos Humanos em organizações públicas, com mais ênfase na variável Motivação.

Da mesma forma, quanto à análise das características avançadas, a Motivação destacouse como a principal função da Avaliação de Desempenho de Recursos Humanos do setor público. Esse fato está ligado à inexistência de um processo de gestão de Recursos Humanos claro e justo, capaz de avaliar e promover a força de trabalho com base no desempenho. Observou-se que, embora existam indicadores de desempenho de Recursos Humanos, a maior parte das pesquisas não vincula os indicadores ao ambiente e às estratégias da organização.

Essa foi apenas uma das falhas de Sistema apontada nas pesquisas, além da falta de definição clara, falta de métricas objetivas, falta de feedback e de aprendizado e falta de envolvimento do usuário. Já em relação ao ciclo de vida da Avaliação de Desempenho de Recursos Humanos, as pesquisas ainda se concentram no estágio inicial referente ao design, cuja conclusão análoga foi apontada por Bourne et al. (2000). Portanto, as pesquisas precisam avançar para a análise dos processos necessários para o funcionamento do Sistema de Avaliação de Desempenho de Recursos Humanos no setor público, de forma a evoluir para os estágios de implementação, uso e revisão, preferencialmente com a participação dos stakeholders.

As delimitações desta pesquisa foram: (i) utilização de artigos em língua inglesa disponíveis em três bases de dados do Portal da Capes, selecionadas e acessíveis de forma gratuita na internet; (ii) utilização de dois comandos de busca específicos; (iii) análise das características básicas e avançadas definidas pelos autores; e (iv) análise com base no julgamento e na interpretação dos autores.

Como sugestões para futuras pesquisas, apontam-se: (i) busca de artigos em outras bases de dados; (ii) desenvolvimento da análise de outras características avançadas; (iii) desenvolvimento da etapa do instrumento Proknow-C referente à análise sistêmica; e (iv) desenvolvimento de pesquisas acerca das oportunidades apontadas na Seção 4.3 deste estudo.

\section{REFERÊNCIAS}

ABU-DOLEH, J.; WEIR, D. Dimensions of performance appraisal systems in Jordanian private and public organizations. The International Journal of Human Resource Management, v. 18 , n. 1, p. 75-84, 2007. [5]

AMIN, M.; ISMAIL, W. K. W.; RASID, S. Z. A.; SELEMANI, R. D. A. The impact of human resource management practices on performance: Evidence from a Public University. The TQM Journal, v. 26, n. 2, 125-142. 2014. [13]

AZMI, I. A. G. Competency-based human resource practices in Malaysian public sector organizations. African Journal of Business Management, v. 4, n. 2, p. 235, 2010. [9] 
BEHN, R. D. Why measure performance? Different purposes require different measures. Public Administration Review, v. 63, n. 5, p. 586-606, 2003.

BITITCI, U. S.; GARENGO, P.; ATES, A.; NUDURUPATI, S. S. Value of maturity models in performance measurement. International Journal of Production Research, v. 53, n. 10, p. 3062-3085, 2015.

BITITCI, U.; GARENGO, P.; DÖRFLER, v.; NUDURUPATI, S. Performance measurement: challenges for tomorrow. International Journal of Management Reviews, v. 14, n. 3, p. 305$327,2012$.

BLACKMAN, D.; BUICK, F.; O'DONNELL, M. Why Performance Management Should Not Be Like Dieting. Australian Journal of Public Administration, v. 76, n. 4, p. 524-528, 2017. [21]

BOURNE, M.; MILLS, J.; WILCOX, M.; NEELY, A.; PLATTS, K. Designing, implementing and updating performance measurement systems. International Journal of Operations \& Production Management, v. 20, n. 7, p. 754-771, 2000.

CARNEIRO-DA-CUNHA, J. A.; HOURNEAUX JR, F.; CORRÊA, H. L. Evolution and chronology of the organizational performance measurement field. International Journal of Business Performance Management, v. 17, n. 2, p. 223-240, 2016.

CHOONG, K. K. Has this large number of performance measurement publications contributed to its better understanding? A systematic review for research and applications. International Journal of Production Research, v. 52, n. 14, p. 4174-4197, 2014.

CONWAY, E.; FU, N., MONKS, K., ALFES, K.; BAILEY; C. Demands or resources? The relationship between HR practices, employee engagement, and emotional exhaustion within a hybrid model of employment relations. Human Resource Management, v. 55, n. 5, p. 901 917, 2016. [15]

COOK, J.; CROSSMAN, A. Satisfaction with performance appraisal systems: a study of role perceptions. Journal of Managerial Psychology, v. 19, n. 5, p. 526-541, 2004. [3]

CRESWELL, J. W. Research Design: Qualitative, Quantitative and Mixed Methods Approaches. 4th ed. Thousand Oaks, CA: Sage, 2014.

DALEY, D. M.; VASU, M. L. Supervisory perceptions of the impact of public sector personnel practices on the achievement of multiple goals: Putting the strategic into human resource management. The American Review of Public Administration, v. 35, n. 2, p. 157-167, 2005. [4]

DUTRA, A.; RIPOLL-FELIU, V. M.; FILLOL, A. G. ENSSLIN, S. R.; ENSSLIN, L. The construction of knowledge from the scientific literature about the theme seaport performance evaluation. International Journal of Productivity and Performance Management, v. 64, n. 2, p. 243-269, 2015. 
ENSSLIN, L.; GIFFHORN, E.; ENSSLIN, S. R.; PETRI, S. M.; VIANNA, W. B. Avaliação do Desempenho de empresas terceirizadas com o uso da metodologia Multicritério de Apoio à Decisão-Construtivista. Pesquisa Operacional, v. 30, n. 1, p.125-152, 2010.

FERREIRA, A.; OTLEY, D. T. The design and use of performance management systems: An extended framework for analysis. Management Accounting Research, v. 20, n. 4, p. 263-282, 2009.

FRANCO-SANTOS, M.; KENNERLEY, M.; MICHELI, P.; MARTINEZ, V.; MASON, S.; MARR, B.; GRAY, D.; NEELY, A. Towards a definition of a business performance measurement system. International Journal of Operations \& Production Management, v. 27, n. 8, p. 784-801, 2007.

FRANCO-SANTOS, M.; LUCIANETTI, L.; BOURNE, M. Contemporary performance measurement systems: A review of their consequences and a framework for research. Management Accounting Research, v. 23, n. 2, p. 79-119, 2012.

FRENCH, P. E.; GOODMAN, D. An assessment of the current and future state of human resource management at the local government level. Review of Public Personnel Administration, v. 32, n. 1, p. 62-74, 2012. [11]

GHALAYINI, A. M.; NOBLE, J. S. The changing basis of performance measurement. International Journal of Operations \& Production Management, v. 16, n. 8, p. 63-80, 1996.

HAILESILASIE, G. Determinants of public employees' performance: evidence from Ethiopian public organizations. International Journal of Productivity and Performance Management, v. 58, n. 3, p. 238-253, 2009. [8]

KREUZBERG, F., VICENTE, E. Para Onde Estamos Caminhando? Uma Análise das Pesquisas em Governança Corporativa. Revista de Administração Contemporânea, v. 23, n. 1, p.43-66, 2018.

LEBAS, M. J. Performance measurement and performance management. International Journal of Production Economics, v. 41, n. 1-3, p. 23-35, 1995.

MATOS, L. D. S.; ENSSLIN, S. R.; ENSSLIN, L. A Review on the Performance Measurement Systems Life Cycle. Lex Localis-Journal of Local Self-Government, v.17, n. 4, p. 939-959, 2019.

MAKHUBELA, M.; BOTHA, P. A.; SWANEPOEL, S. Employees' perceptions of the effectiveness and fairness of performance management in a South African public sector institution. SA Journal of Human Resource Management, v. 14, n. 1, p. 1-11, 2016. [17]

MANOLOPOULOS, D. An evaluation of employee motivation in the extended public sector in Greece. Employee Relations, v. 30, n. 1, p. 63-85, 2008. [7]

MELNYK, S. A.; BITITCI, U.; PLATTS, K.; TOBIAS, J.; ANDERSEN, B. Is performance measurement and management fit for the future? Management Accounting Research, v. 25, n. 2, p. 173-186, 2014. 
MELTON, E. K.; MEIER, K. J. For the want of a nail: The interaction of managerial capacity and human resource management on organizational performance. Public Administration Review, v. 77, n. 1, p. 118-130, 2017. [19]

MICHELI, P.; MARI, L. The theory and practice of performance measurement. Management Accounting Research, v. 25, n. 2, p. 147-156, 2014.

MOSTAFA, A. M. S.; GOULD-WILliAMS, J. S.; BOTTOMLEY, P. High-performance human resource practices and employee outcomes: the mediating role of public service motivation. Public Administration Review, v. 75, n. 5, p. 747-757, 2015. [14]

NEELY, A.; GREGORY, M.; PLATTS, K. Performance measurement system design: a literature review and research agenda. International Journal of Operations \& Production Management, v. 15, n. 4, p. 80-116, 1995.

NEELY, A. The performance measurement revolution: why now and what next? International Journal of Operations \& Production Management, v. 19, n. 2, p. 205-228, 1999.

NUDURUPATI, S. S; BITITCI, U. S.; KUMAR, V.; CHAN, F.T. State of the art literature review on performance measurement. Computers \& Industrial Engineering, v. 60, n. 2, p. 279-290, 2011.

PLANO DIRETOR DA REFORMA DO APARELHO DO ESTADO (1995). Brasília, DF. Disponível em: <http://www.biblioteca.presidencia.gov.br/publicacoesoficiais/catalogo/fhc/plano-diretor-da-reforma-do-aparelho-do-estado-1995.pdf/view>. Acesso em: 19 dez. 2018.

RICHARDSON, R. J. Pesquisa Social: métodos e técnicas. 3. ed. São Paulo: Atlas, 1999.

SELDEN, S. C.; JACOBSON, W.; AMMAR, S. H.; WRIGHT, R. H. A new approach to assessing performance of state human resource management systems: A multi-level fuzzy rulebased system. Review of Public Personnel Administration, v. 20, n. 3, p. 58-74, 2000. [1]

SONGSTAD, N. G.; LINDKVIST, I.; MOLAND, K. M. CHIMHUTU, V.; BLYSTAD, A. Assessing performance enhancing tools: experiences with the open performance review and appraisal system (OPRAS) and expectations towards payment for performance (P4P) in the public health sector in Tanzania. Globalization and Health, v. 8, n. 1, p. 33, 2012. [10]

SRIVASTAVA, A. P.; DHAR, R. L. Impact of Leader member exchange, human resource management practices and psychological empowerment on extra role performances: the mediating role of organisational commitment. International Journal of Productivity and Performance Management, v. 65, n. 3, p. 351-377, 2016. [16]

TANWIR, M.; CHAUDHRY, A. Reforming a broken system: a new performance evaluation system for Pakistan civil servants. Pakistan Development Review, v. 55, n. 1, p. 49, 2016. [18] 
TER BOGT, H. J. Performance evaluation styles in governmental organizations: How do professional managers facilitate politicians' work? Management Accounting Research, v. 14, n. 4, p. 311-332, 2003. [2]

THIEL, G. G.; ENSSLIN, S. R.; ENSSLIN, L. Street Lighting Management and Performance Evaluation: Opportunities and Challenges. Lex Localis, v. 15, n. 2, p. 303, 2017.

VALMORBIDA, S. M. I.: CARDOSO, T. L.; ENSSLIN, S. R. Rankings universitários: análise dos indicadores utilizados. Sociedade, Contabilidade e Gestão, v. 10, n. 2, p. 88-102, 2015.

VALMORBIDA, S. M. I.; ENSSLIN, S. R. Performance evaluation of university rankings: literature review and guidelines for future research. International Journal of Business Innovation and Research, v. 14, n. 4, p. 479-501, 2017.

VAN CAMP, J.; BRAET, J. Taxonomizing performance measurement systems' failures. International Journal of Productivity and Performance Management, v. 65, n. 5, p. 672-693, 2016.

VAN RINSUM, M.; VERBEETEN, F. H. M. The impact of subjectivity in performance evaluation practices on public sector managers' motivation. Accounting and Business Research, v. 42, n. 4, p. 377-396, 2012. [12]

VERBEETEN, F. H. M. Performance management practices in public sector organizations: Impact on performance. Accounting, Auditing \& Accountability Journal, v. 21, n. 3, p. 427 454, 2008. [6]

VERMEEREN, B. Influencing public sector performance: studying the impact of ability-, motivation-and opportunity-enhancing human resources practices on various performance outcomes in the public sector. International Review of Administrative Sciences, v. 83, n. 4, p. 717-737, 2017. [20] 